\title{
Sanjeevini: a freely accessible web-server for target directed lead molecule discovery
}

\author{
B Jayaram ${ }^{1,2,3^{*}}$, Tanya Singh ${ }^{1,2}$, Goutam Mukherjee ${ }^{1,2}$, Abhinav Mathur $^{2}$, Shashank Shekhar ${ }^{2}$, Vandana Shekhar ${ }^{2}$ \\ From Asia Pacific Bioinformatics Network (APBioNet) Eleventh International Conference on Bioinformatics \\ (InCoB2012) \\ Bangkok, Thailand. 3-5 October 2012
}

\begin{abstract}
Background: Computational methods utilizing the structural and functional information help to understand specific molecular recognition events between the target biomolecule and candidate hits and make it possible to design improved lead molecules for the target.

Results: Sanjeevini represents a massive on-going scientific endeavor to provide to the user, a freely accessible state of the art software suite for protein and DNA targeted lead molecule discovery. It builds in several features, including automated detection of active sites, scanning against a million compound library for identifying hit molecules, all atom based docking and scoring and various other utilities to design molecules with desired affinity and specificity against biomolecular targets. Each of the modules is thoroughly validated on a large dataset of protein/DNA drug targets.

Conclusions: The article presents Sanjeevini, a freely accessible user friendly web-server, to aid in drug discovery. It is implemented on a tera flop cluster and made accessible via a web-interface at http://www.scfbio-iitd.res.in/ sanjeevini/sanjeevini.jsp. A brief description of various modules, their scientific basis, validation, and how to use the server to develop in silico suggestions of lead molecules is provided.
\end{abstract}

\section{Background}

One of the main challenges in structure based drug discovery is to utilize the structural and chemical information of the drug targets and their ligand binding sites to create new molecules with high affinity and specificity, bioavailability and possibly least toxicity [1]. Computer aided drug discovery, in this context, is proving to be particularly invaluable [2-89]. The rapid ascent and acceptance of this methodology has been feasible due to advances in software and hardware. Sanjeevini server has been developed as an enabler for drug designers to address issues of affinity and selectivity of candidate molecules against drug targets with known structures. Sanjeevini comprises several modules with different functions, such as automated identification of potential binding sites (active sites) of ligands on the

\footnotetext{
* Correspondence: bjayaram@chemistry.iitd.ac.in

'Department of Chemistry, Indian Institute of Technology, Hauz Khas, New Delhi-110016, India

Full list of author information is available at the end of the article
}

biomolecular target [90], a rapid screening of a million molecule database/natural product library [91] for identifying good candidates for any target protein, optimization of their geometries [92] and determination of partial atomic charges using quantum chemical methods [92,93], assignment of force field parameters to ligand [94] and the target protein/DNA [95], docking of the candidates in the active site of the drug target via Monte Carlo methods $[90,96]$, estimation of binding free energies through empirical scoring functions [97-99], followed by rigorous analyses of the structure and energetics $[100,101]$ of binding for further lead optimization. The computational pathway created rolls over into an automated pipe-line for lead design, if desired. The software takes three dimensional structure of the target protein or nucleotide sequence of DNA as an input; the remaining functionalities are built into the software suite to arrive at the structure and desired binding free energy of the protein/DNA-candidate molecule complex. The methodology treats biomolecular 
target and candidate molecules at the atomic level and solvent as a dielectric continuum. Validation studies on a large number of protein-ligand and DNA-ligand complexes suggest that performance of Sanjeevini is at the state of the art. The software is freely accessible over the net. We describe here as to how to harness the server for accelerating lead molecule discovery.

The front end of Sanjeevini website is shown in Figure 1 and the overall architecture of the software suite is given in Figure 2. Sanjeevini is a user friendly web interface where the demands on the user have been reduced to uploading of the target protein coordinates file or DNA sequence and the ligand molecule. The software protocol automatically standardizes the input formats of the biomolecule. Additionally, it determines the branch of pathway (Figure 2) that has to be followed (protein with known binding sites/protein with unknown binding site) by analyzing the target protein file and redirects the job instance for the same. Thus, any kind of overhead to the user to pre-format the input files for docking and scoring is removed. User can upload the desired ligand molecule either by drawing the molecule or by cultivating the molecular databases incorporated into Sanjeevini. There are three different molecular databases in-built in Sanjeevini namely NRDBSM containing 17000 molecules [82], a million molecule database containing one million small molecules, and a natural product database with 0.1 million natural products and their derivatives [91]. The molecules present in the database are Lipinski compliant $[102,103]$. Sanjeevini database of small organic molecules and the natural product database are localized on the linux clusters. Based on the user's choice of the physicochemical properties of interest including molecular weight, $\log P$, number of hydrogen bond donor and acceptor atoms, overall formal charge of the molecule and many more, a list of all the molecules falling in the ranges provided by the user are displayed in a downloadable form. However, if a self drawn molecule is uploaded by the user, then one can check its bioavailability by clicking the Lipinski's rule option in Sanjeevini. The program predicts the physicochemical properties (Lipinski's rules) of the uploaded ligand molecule. If the binding site of the uploaded target protein is known and the coordinates of the protein-ligand complex are available in RCSB [104], then one can quickly check the binding affinity of the uploaded ligand and can also scan databases of small organic molecules [91] against any target protein by clicking the RASPD option (Mukherjee and Jayaram, Manuscript in preparation). The RASPD module takes 10-15 minutes in screening the database against a target protein. The docking and scoring module of Sanjeevini performs a series of computational steps such as preparation of the protein and the ligand from the files uploaded, docks the candidate molecule at the bind- ing site via a Monte Carlo algorithm, minimizes and scores the docked complex, in an automated mode. The average time taken in the protein and ligand preparation and the Monte Carlo docking program ranges from 1-3 minutes. The Monte Carlo docking program is implemented in a parallel processing mode. The docked complexes are further minimized using the parallel version of Sander module of AMBER [105] which scales best on 32 processors. Sanjeevini programs run on linux clusters having infiniband network resources which facilitate a high through put distribution of the data across the various nodes. On an average, the total time taken by the complete docking and scoring protocol ranges from 5-20 minutes depending on the size of the protein and the ligand. The above time frames reported correspond to performance on a 32 processors cluster. A benchmark test on 8,16 and 32 processors showed that the entire docking and scoring module scaled best on 32 processors. Memory consumption and $\mathrm{I} / \mathrm{O}$ issues are minimal during program execution. The time taken also depends on the load on the server. Currently 80 processors are dedicated for jobs submitted to Sanjeevini. For each molecule five docked structures representing the poses of the molecule in the active site along with the binding affinity are emailed to user. However, if the binding sites are unknown in the protein, the $A A D S$ [90] option predicts ten hot spots/binding sites in the protein and docks the uploaded ligand molecule at all the ten predicted sites. Five docked structures representing the poses of the ligand molecule in the binding site along with their binding free energies are reported back to the user. The above docked structures may be treated as a reference protein-ligand complex which can be given as an input to scan the publicly accessible version of commercially-available compound database http://zinc. docking.org/ through RASPD protocol to arrive at suggestions of additional hit molecules against the target protein with unknown binding site information. A new cycle of design, docking and scoring for an iterative improvement of the candidate molecule can be initiated for desired affinities and scaffolds.

Target-molecule complexes with high binding affinity can be subjected to molecular dynamics simulations [101] in propitious cases, to investigate the effect of conformational flexibility, solvent, salt and entropic factors. About 100 or more structures may be collected over the trajectories and converged average binding free energies of the complexes may be obtained. Further post facto energy component analyses of the targetligand complex can help in chemical modifications on the candidate molecule for enhancing the binding affinities. Different modules described above have been incorporated, which work in a pipeline as depicted in the architecture (Figure 2). 


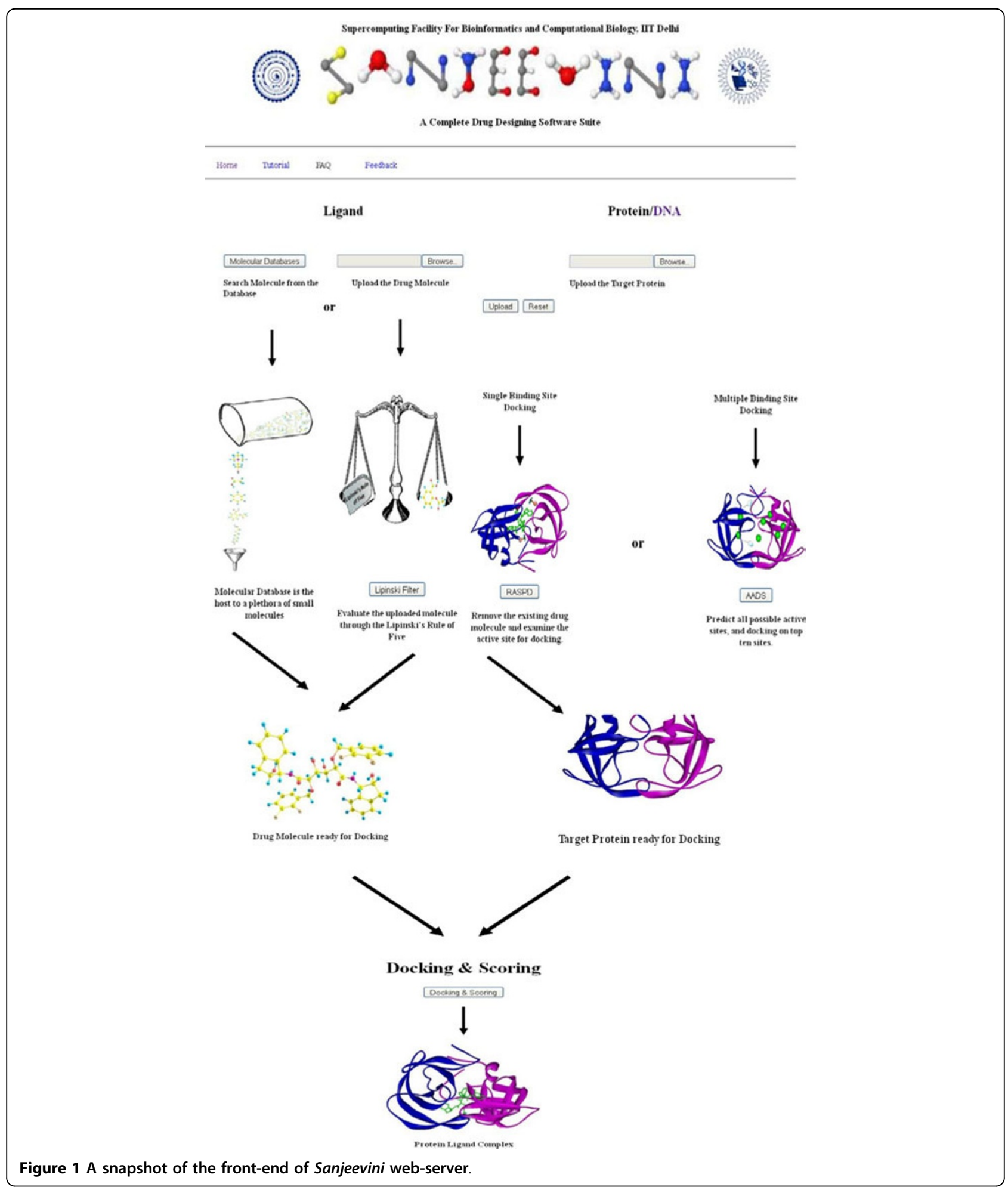

A brief description of a few frequently used modules in Sanjeevini

Sanjeevini software comprises several modules with high accuracies, working in a pipeline, and given a protein/ DNA as the drug target, and a ligand molecule which is optional to the software suite, it helps in designing lead molecules.

Scoring function

Sanjeevini comprises three scoring functions christened Bappl [97], Bappl-Z [98] and PreDDICTA [99] for 


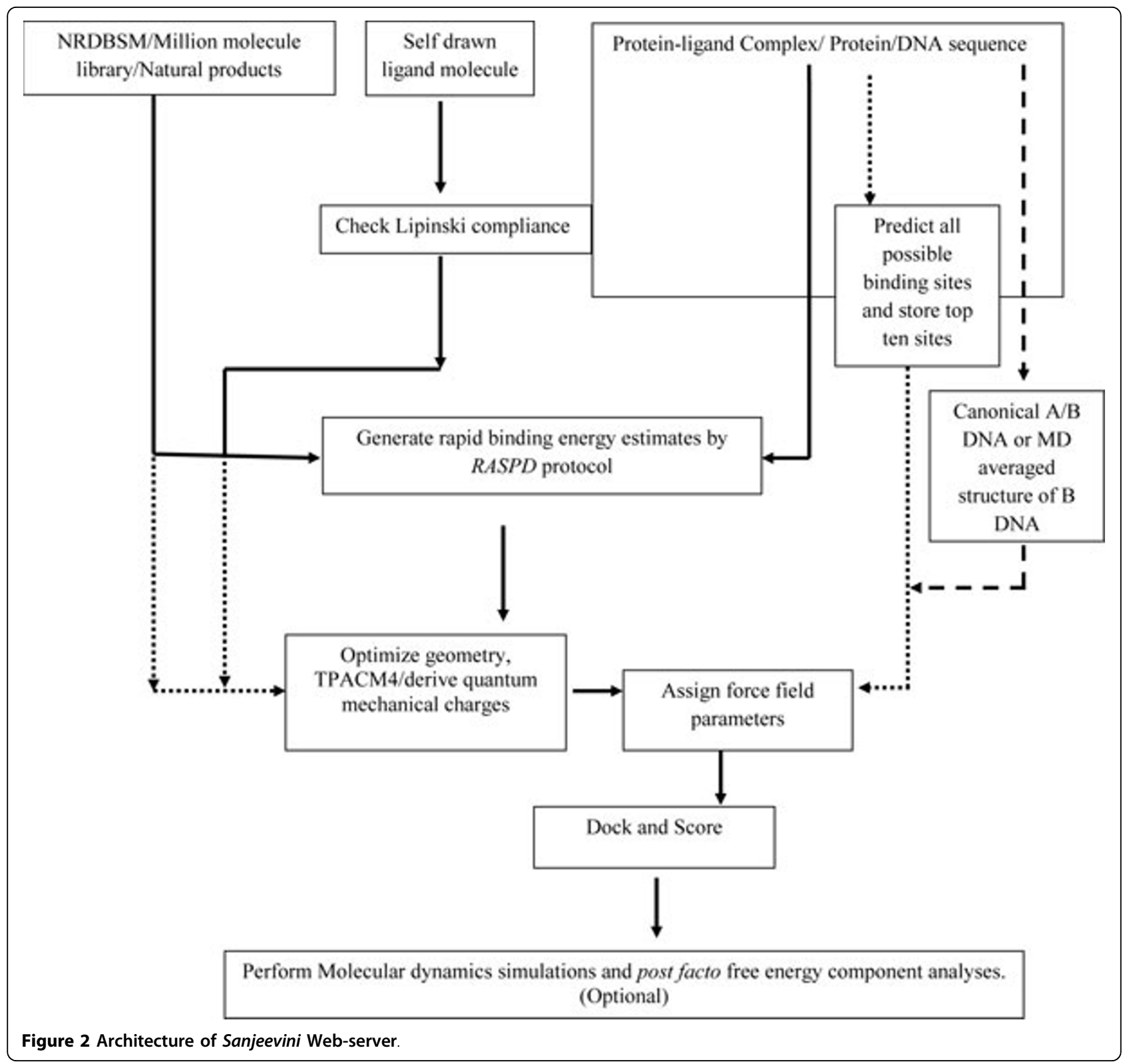

protein-ligand complexes, Zn containing metalloproteinase-ligand complexes and DNA-ligand complexes respectively. Bappl is an all atom energy based empirical scoring function comprising electrostatics, van der Waals, desolvation and loss of conformational entropy of protein side chains upon ligand binding. Bappl- $Z$ scores protein-ligand complexes with $\mathrm{Zn}$ as the metal ion in the binding site in which a non-bonded approach to model the interactions of the zinc ion with all other atoms of the protein-ligand complex has been employed along with the four terms described for Bappl. PreDDICTA is an all atom energy based scoring function which computes binding affinity of a DNA oligomer with a non-covalently bound drug molecule in the minor groove. The function is a combination of electrostatics, steric complementarities, entropic and solvent effects, including hydrophobicity. There are very few high accuracy scoring functions reported in literature for DNA-ligand complexes and, PreDDICTA thus provides a strong platform for designing molecules binding specifically to DNA. The program takes DNA-ligand complex as an input and outputs binding free energies associated with the complex.

\section{Docking Module}

The docking module of Sanjeevini comprises three programs christened ParDOCK [96], AADS [90] and DNADock $[96,99]$. ParDock is an all atom energy-based Monte Carlo, protein-ligand docking algorithm. The module requires a reference protein-ligand complex (target protein 
bound to a reference ligand at its binding site) as an input along with the candidate molecule to be docked. The algorithm docks the ligand molecule to the reference protein and outputs five docked structures representing different poses of ligand molecule along with the predicted binding free energies of the docked poses using Bappl/BapplZ scoring function. The program is in-built into Sanjeevini software for docking ligand molecules to the target protein for which crystal structure of the protein-ligand complex is available in literature. $A A D S$ (An automated active site identification, docking and scoring protocol for protein targets based on physico-chemical descriptors) predicts all potential binding sites in a protein and docks the input ligand molecule at the top ten predicted binding sites. Eight docked structures are generated at each of these ten sites and scored using Bappl/BapplZ scoring function. Five out of the eighty structures, favorable energetically are emailed back to the user along with the binding free energy values. The program has been tested previously [90] on more than 600 protein-ligand complexes with known binding site information. $A A D S$ predicted the true binding sites within the top ten sites with $100 \%$ accuracy. A blind docking on 170 protein targets [90] with known binding sites and known experimental binding free energies associated with the complexed ligands was also performed. The methodology restored the binding pose of the ligands to their native binding sites in the above 170 complexes with an accuracy of $90 \%$ for the top ranked docked structure and the predicted binding free energies of the top most docked structure correlated well with experiment (correlation coefficient $\sim 0.82$; see Figure F4 of [90]). The RMSD (Root Mean Square Deviation) between crystal and the docked structures in more than $80 \%$ of the cases is within $2 \AA$ (Figure F5 of [90]). DNADock is an all atom Monte Carlo based docking algorithm which has been implemented in parallel mode and is incorporated into the software suite. The program takes nucleotide sequence and the candidate ligand molecule as input, generates canonical A or B DNA [123] or an average molecular dynamics B DNA structure [124,125] based on the user's choice, docks the candidate ligand molecule in the minor groove of DNA, and scores the docked structures through PreDDICTA scoring function. Five docked structures with their binding free energy values are reported back to the user.

$R A S P D$ (A rapid identification of hit molecules for target proteins via physico-chemical descriptors) is a computationally fast protocol for identifying hit molecules for any target protein. The methodology establishes complementarity in physico-chemical descriptor space of the target protein and the candidate molecule via a QSAR type approach and rapidly generates a reasonable estimate of the binding energy. The accuracies of RASPD are discussed elsewhere (Mukherjee and Jayaram manuscript in preparation).

\section{Results and discussion}

The scoring functions of Sanjeevini software were validated on a large dataset comprising 366 protein-ligand complexes, Zn-containing metalloproteinase-ligand complexes and DNA-ligand complexes which includes 335 crystal structures and 31 modeled structures. The PDB IDs of the validation dataset with the experimental and predicted binding free energies are provided in Additional file 1 . A correlation coefficient of $r=0.88$ was obtained between the experimental and predicted binding free energies on the above dataset as shown in Figure 3.

Some of the published results of scoring functions for protein-ligand complexes originating in physics based or knowledge based methods include DFIRE $(\mathrm{r}=0.63)$ [106], $\times$ SCORE $(r=0.77)$ [107], SMoG $(r=0.79)$ [108], $\operatorname{BLEEP}(r=0.74)$ [109], PMF $(r=0.78)$ [110], SCORE $(r=$ 0.81) [111], LUDI $(r=0.83)$ [112], ChemScore $(r=0.84)$ [113], Ligscore $(r=0.87)$ [114], KGS comprising of both $\mathrm{X}$-Score and PLP ( $\mathrm{r}=0.82)$ [115]. Sanjeevini scoring function for protein-ligand complexes yielded a correlation coefficient $(r)$ of 0.87 . There are very few scoring functions reported in literature for DNA-ligand complexes. One among them is the KS score $(r=0.68)$ [116]. Sanjeevini scoring function for DNA-ligand complexes has been tested on 39 DNA-ligand complexes involving no training which yielded a correlation coefficient of 0.90. PreDDICTA has been reported to perform better than some of the existing scoring functions for DNAligand complexes in literature [116]. Scoring functions for zinc containing metalloprotein-ligand complexes reported in literature include the work of Raha et al., $\left(R^{2}=0.69\right)$ [117], Hou et al., $\left(R^{2}=0.85\right)$ [118], Hu et al., (0.50) [119], Rizzo et al., $\left(R^{2}=0.74\right)$ [120], Khandelwal et al., $\left(R^{2}=0.90\right)$ [121]. Sanjeevini yielded a correlation coefficient $\mathrm{R}^{2}=0.82$ on zinc-containing metalloprotein ligand complexes. The overall correlation coefficient of Sanjeevini for protein/DNA-ligand complexes (Figure 3) is 0.88 .

The docking module of Sanjeevini has been validated on a dataset of $335 \mathrm{DNA}$ /protein targets with known binders and structures and known experimental binding free energies. The predicted binding free energies of the top ranked docked structures reported by Sanjeevini (Additional File 2) were compared with experiment (Figure 4) and also the RMSDs (root mean square deviations) between the crystal structures and the top ranked docked structures (Figure 5). The high accuracies obtained by Sanjeevini as evident from a correlation coefficient of $\mathrm{r}=$ 0.83 in Figure 4 and RMSDs lying within $2 \AA$ in Figure 5, provide a strong platform to design drug-like molecules. 


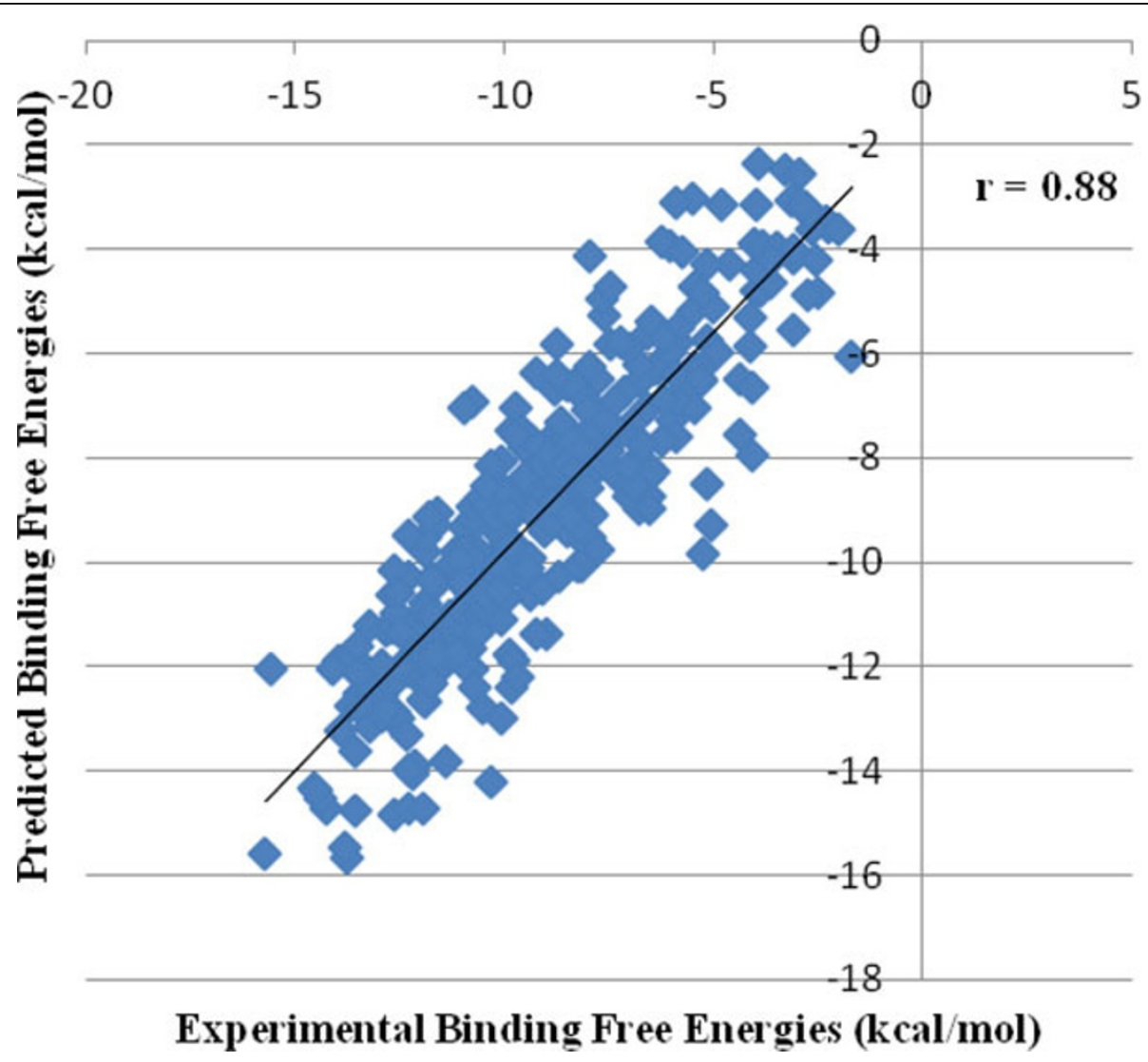

Figure 3 Correlation between experimental and predicted binding free energies for 366 protein/DNA-ligand complexes.

For protein-ligand complexes Autodock Vina [5] has been reported to predict the top most structure within $2 \AA$ RMSD from the native complex with $80 \%$ accuracy. In a recent work of Zhong-Ru Xie et al. DrugScore ${ }^{C S D}$ scoring function was compared with some of the known scoring functions in literature [122] and was reported to perform better than others giving an accuracy of $87 \%$ in predicting the top most docked structure within an RMSD of $2 \AA$ from crystal structure. The docking and the scoring module of Sanjeevini yielded $90 \%$ accuracy in predicting the top most docked structure within $2 \AA$ RMSD from crystal structure on a large dataset (335 complexes: Figure 5).

\section{Case studies}

While designing new molecules for a target protein/ DNA, user may have experimental $\left(\mathrm{K}_{\mathrm{i}} / \mathrm{IC} 50 / \mathrm{K}_{\mathrm{d}}\right)$ values of known binders reported in the literature. Before designing new candidate molecules against a target protein/ DNA, we propose to the Sanjeevini user to predict the binding free energies of the known binders and plot a correlation graph between the experimental and predicted binding free energies. This would give a relative understanding of the predicted binding free energies vis- a-vis experiment, helping in discriminating between drug-like and non-drug-like molecules against a given target. With this proposal, we present a few case studies on an important class of drug targets which can set examples for the Sanjeevini users to utilize the same methodology on various drug targets to come up with suggestions of hit molecules.

Case 1: Protein targets with known binding site information Majority of drugs deposited in RCSB have been cocrystallized with a single protein or more than one protein [126] yielding the drug binding site for the target protein. The first case study was on protein targets for which structures of the protein-ligand complexes were available in the database specifying the binding site. Serine proteinases play an important role in many biological processes [127]. For instance trypsin helps in digestion and thrombins in the blood coagulation cascade. The above class of enzymes is implicated in a wide spectrum of diseases which are related to a malfunctioning in this regulation. We predicted the binding energies of 12 trypsin binding molecules. In addition, some of the known synthetic inhibitors [128] of bovine pancreatic trypsins, PDBID 1S0R were also docked and scored. The predicted binding free energies associated with the top ranked 


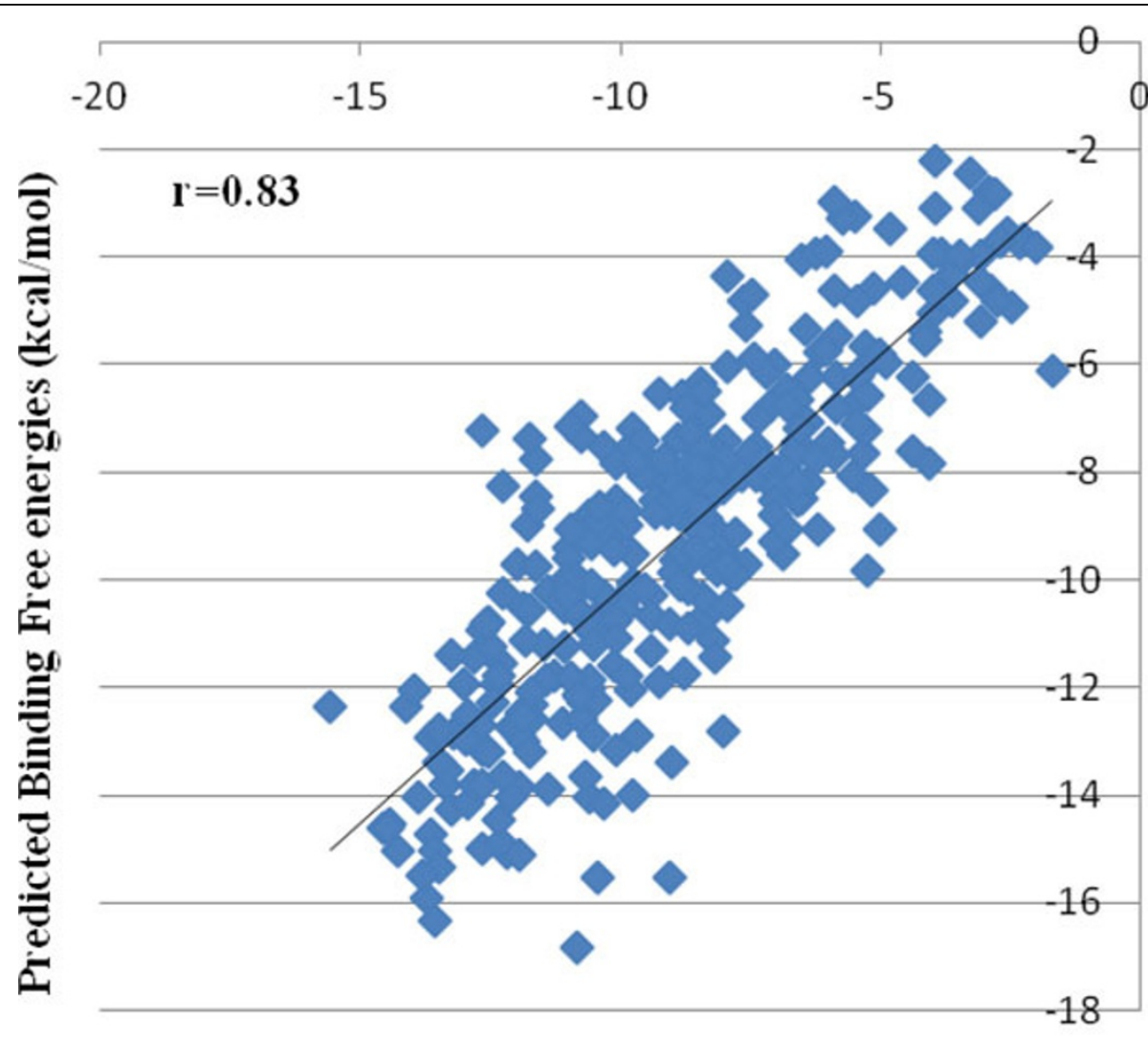

Experimental Binding Free Energies (kcal/mol)

Figure 4 Correlation between experimental and predicted binding free energies of the top ranked docked structures for 335 protein/ DNA-ligand complexes.

docked complex for all the above data are shown in Table 1. A correlation coefficient of $r=0.92$ was obtained between the experimental and predicted binding free energies as illustrated in Figure 6.

\section{Case 2: Input as a target protein with unknown binding} site and a candidate ligand

When the user has the 3D coordinates of a target protein, either as deposited in the protein data bank or as a modeled structure with no binding site information, the $A A D S$ pathway of Sanjeevini gets pre-selected to come up with suggestions of hit molecules. We performed a case study on the trypsin binding inhibitors considered in the first case study. For the twelve protein structures complexed with ligand and known binding site information, we deliberately removed the ligands from the target proteins and uploaded the target to Sanjeevini for a blind docking with the ligand. For Bovine pancreatic trypsin receptor, a structure with unknown binding site information (PDBID 1S0Q) is also available in the literature $[128,129]$ along with a protein-ligand complex (PDBID 1SOR) which was taken as an input in the first case study.
The target receptor with unknown binding site and its synthetic inhibitors were given as input to Sanjeevini. $A A D S$ module gave an output of five docked structures along with binding free energies. A total of 230 docking runs corresponding to 10 binding sites for each target were performed in an automated mode by Sanjeevini in the above case study for the 23 trypsin binding molecules. We compared the predicted binding free energies of the energetically top ranked structure for each target (shown in Table 1) and plotted a correlation graph between the experimental and predicted binding free energies (shown in Figure 7).

In the Bovine pancreatic trypsins, the amino acids mainly involved in interactions with the ligand molecules are reported to be Ser 172, Asp 171 and Gly 196 in the target protein (PDBID 1S0R) [104]. We visualized the docked structures obtained from the above blind docking studies of trypsin inhibitors against the target (PDB ID 1S0Q) to make sure if the top ranked docked structures have the native ligand pose restored in the native binding site of target. A good estimate of the binding free energies 


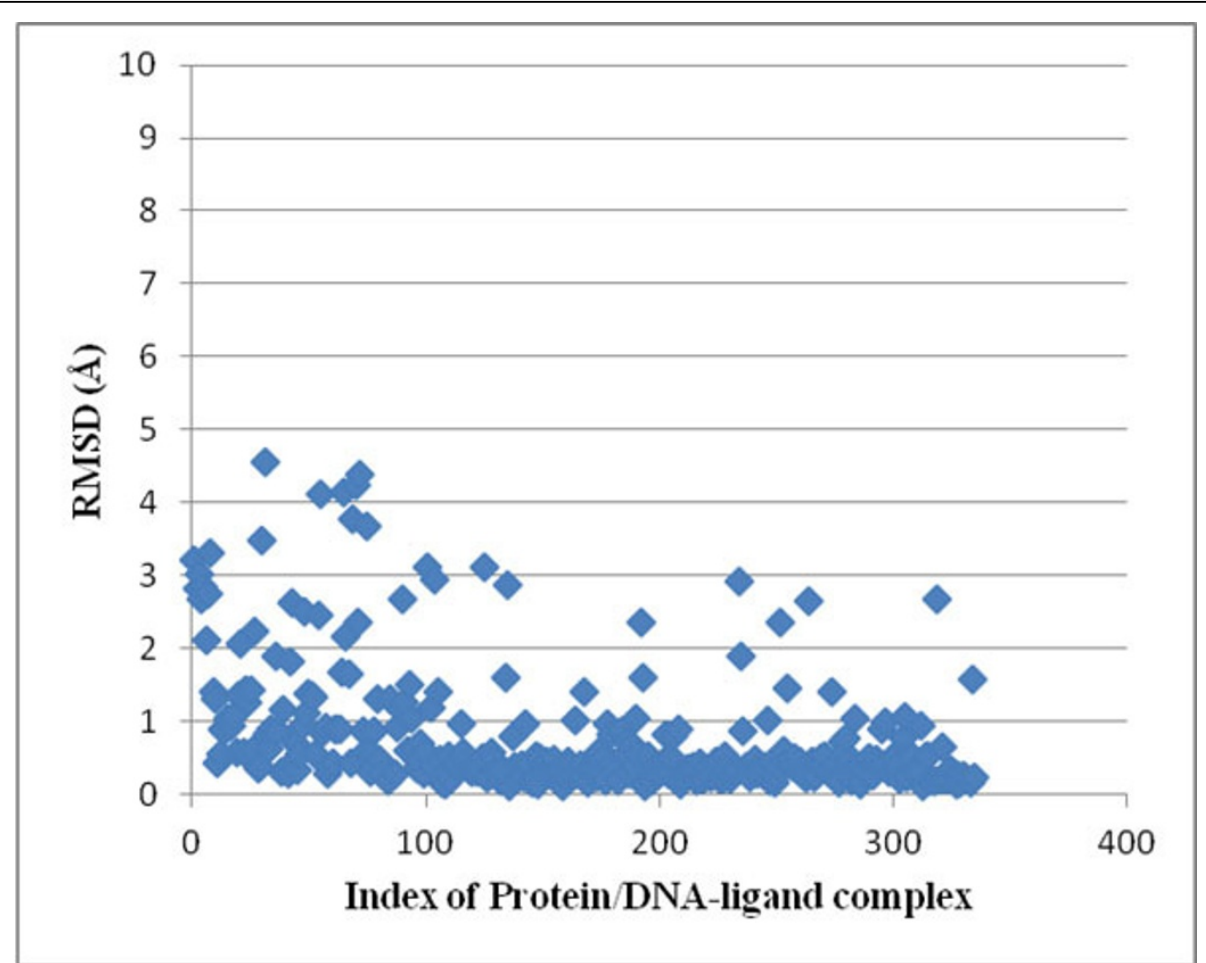

Figure 5 Root Mean Square Deviation between the crystal structure and the top ranked docked structure for 335 protein/DNA-ligand complexes.

Table 1 Docking and scoring studies of experimentally reported trypsin binding molecules using Sanjeevini

\begin{tabular}{|c|c|c|c|c|c|}
\hline SI. No. & PDBID $^{a}$ & Ligand (Molecular formula) & EXBFE (kcal/mol)\# & PBFE (kcal/mol) ${ }^{\mathbf{b}}$ & $\begin{array}{c}\text { PBFE } \\
(\mathrm{kcal} / \mathrm{mol})^{c}\end{array}$ \\
\hline 1 & 1BRA & $\mathrm{C}_{7} \mathrm{H}_{8} \mathrm{~N}_{2}$ & -2.496 & -4.92 & -4.59 \\
\hline 2 & 1FOT & $\mathrm{C}_{19} \mathrm{H}_{19} \mathrm{~N}_{5} \mathrm{O}_{4} \mathrm{~S}_{2}$ & -8.29 & -6.92 & -7.35 \\
\hline 3 & $1 F O U$ & $\mathrm{C}_{27} \mathrm{H}_{30} \mathrm{~N}_{4} \mathrm{O}_{3}$ & -9.89 & -8.98 & -6.96 \\
\hline 4 & $1 \mathrm{MTW}$ & $\mathrm{C}_{26} \mathrm{H}_{28} \mathrm{~N}_{4} \mathrm{O}_{3}$ & -10.076 & -7.84 & -6.64 \\
\hline 5 & $1 \mathrm{PPC}$ & $\mathrm{C}_{27} \mathrm{H}_{31} \mathrm{~N}_{5} \mathrm{O}_{4} \mathrm{~S}$ & -8.8 & -8.46 & -6.85 \\
\hline 6 & $1 \mathrm{TNH}$ & $\mathrm{C}_{7} \mathrm{H}_{9} \mathrm{FN}$ & -4.59 & -4.49 & -4.28 \\
\hline 7 & $1 \mathrm{TNI}$ & $\mathrm{C}_{10} \mathrm{H}_{15} \mathrm{~N}$ & -2.32 & -3.74 & -3.53 \\
\hline 8 & $1 T N J$ & $\mathrm{C}_{8} \mathrm{H}_{12} \mathrm{~N}$ & -2.67 & -3.72 & -3.77 \\
\hline 9 & 1TNK & $\mathrm{C}_{9} \mathrm{H}_{14} \mathrm{~N}$ & -2.03 & -3.81 & -3.51 \\
\hline 10 & $1 \mathrm{TNL}$ & $\mathrm{C}_{9} \mathrm{H}_{12} \mathrm{~N}$ & -2.56 & -3.56 & -3.99 \\
\hline 11 & $1 \mathrm{TPP}$ & $\mathrm{C}_{10} \mathrm{H}_{12} \mathrm{~N}_{2} \mathrm{O}_{3}$ & -7.95 & -6.05 & -5.55 \\
\hline 12 & ЗРТВ & $\mathrm{C}_{7} \mathrm{H}_{8} \mathrm{~N}_{2}$ & -6.46 & -5.36 & -5.27 \\
\hline 13 & $1 \mathrm{SOR} / 1 \mathrm{SOQ}$ & $\mathrm{C}_{8} \mathrm{H}_{10} \mathrm{~N}_{3} \mathrm{O}_{1}$ & -5.71 & -5.25 & -5.59 \\
\hline 14 & 1SOR/1SOQ & $\mathrm{C} 8 \mathrm{H} 11 \mathrm{~N} 2 \mathrm{O} 1$ & -6.04 & -5.37 & -5.51 \\
\hline 15 & 1SOR/1SOQ & $\mathrm{C} 7 \mathrm{H} 10 \mathrm{~N} 3$ & -6.95 & -5.16 & -5.99 \\
\hline 16 & 1SOR/1SOQ & C7H9N2 & -6.35 & -5.26 & -5.12 \\
\hline 17 & 1SOR/1SOQ & $\mathrm{C} 8 \mathrm{H} 11 \mathrm{~N} 2$ & -6.59 & -5.33 & -5.56 \\
\hline 18 & 1SOR/1SOQ & $\mathrm{C} 9 \mathrm{H} 13 \mathrm{~N} 2$ & -6.07 & -5.01 & -5.41 \\
\hline 19 & 1SOR/1SOQ & $\mathrm{C} 10 \mathrm{H} 15 \mathrm{~N} 2$ & -6.14 & -5 & -5.55 \\
\hline 20 & 1SOR/1SOQ & $\mathrm{C}_{10} \mathrm{H}_{15} \mathrm{~N}_{2}$ (iso) & -5.42 & -5.26 & -5.79 \\
\hline 21 & 1SOR/1SOQ & $\mathrm{C}_{11} \mathrm{H}_{17} \mathrm{~N}_{2}$ & -6.26 & -5 & -6.08 \\
\hline 22 & 1SOR/1SOQ & $\mathrm{C}_{12} \mathrm{H}_{19} \mathrm{~N}_{2}$ & -6.5 & -5.45 & -6.55 \\
\hline 23 & $1 \mathrm{SOR} / 1 \mathrm{SOQ}$ & $\mathrm{C}_{13} \mathrm{H}_{21} \mathrm{~N}_{2}$ & -6.97 & -5.82 & -6.53 \\
\hline
\end{tabular}

\# Experimental binding free energies of trypsin binding molecules.

a Protein Data Bank ID

${ }^{b}$ Predicted binding free energies of trypsin binding molecules in Case Study 1.

c Predicted binding free energies of trypsin binding molecules in Case Study 2. 


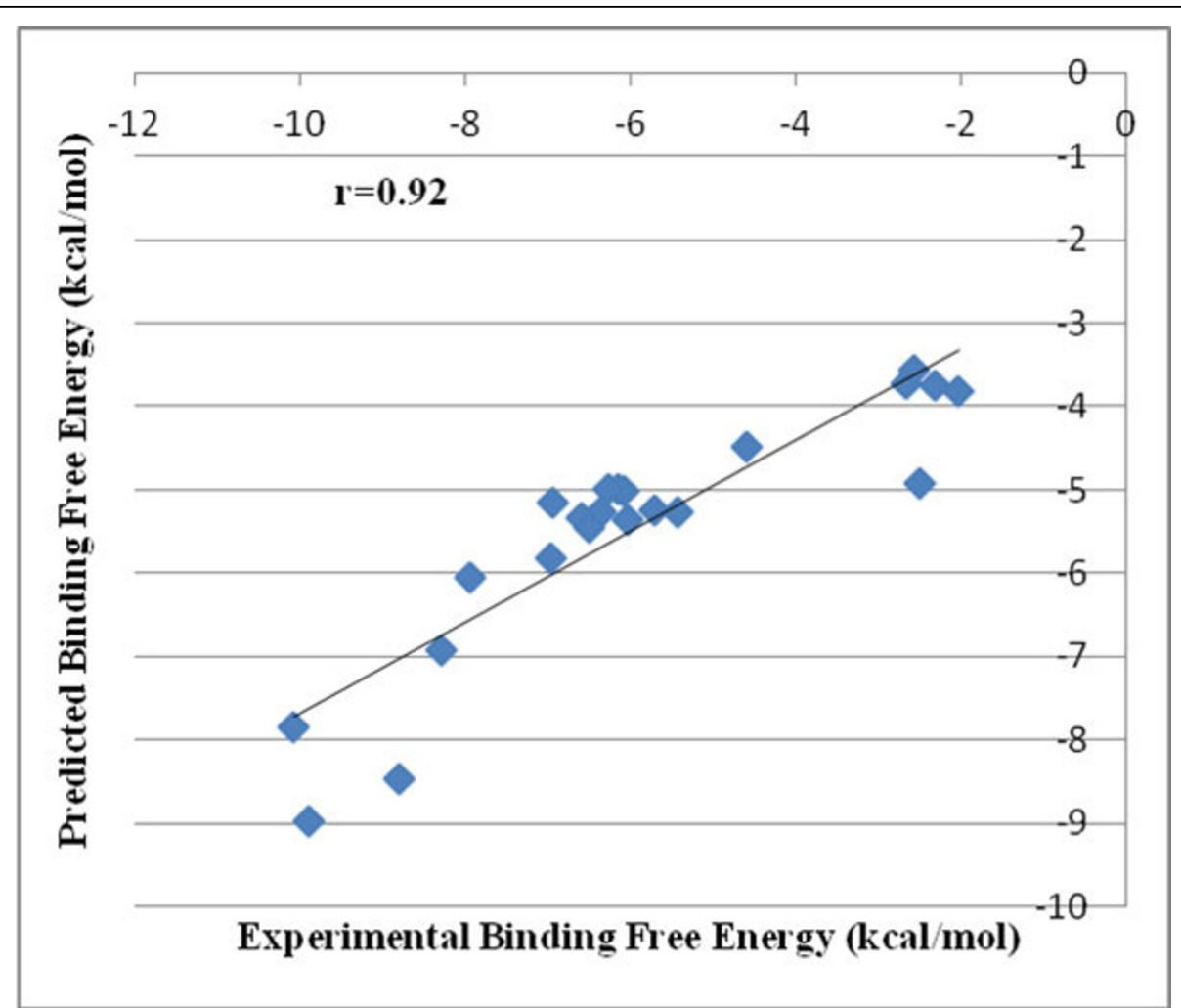

Figure 6 Correlation between experimental and predicted binding free energies of the top ranked docked structures for 23 trypsin binding molecules with known binding site information in the target protein.

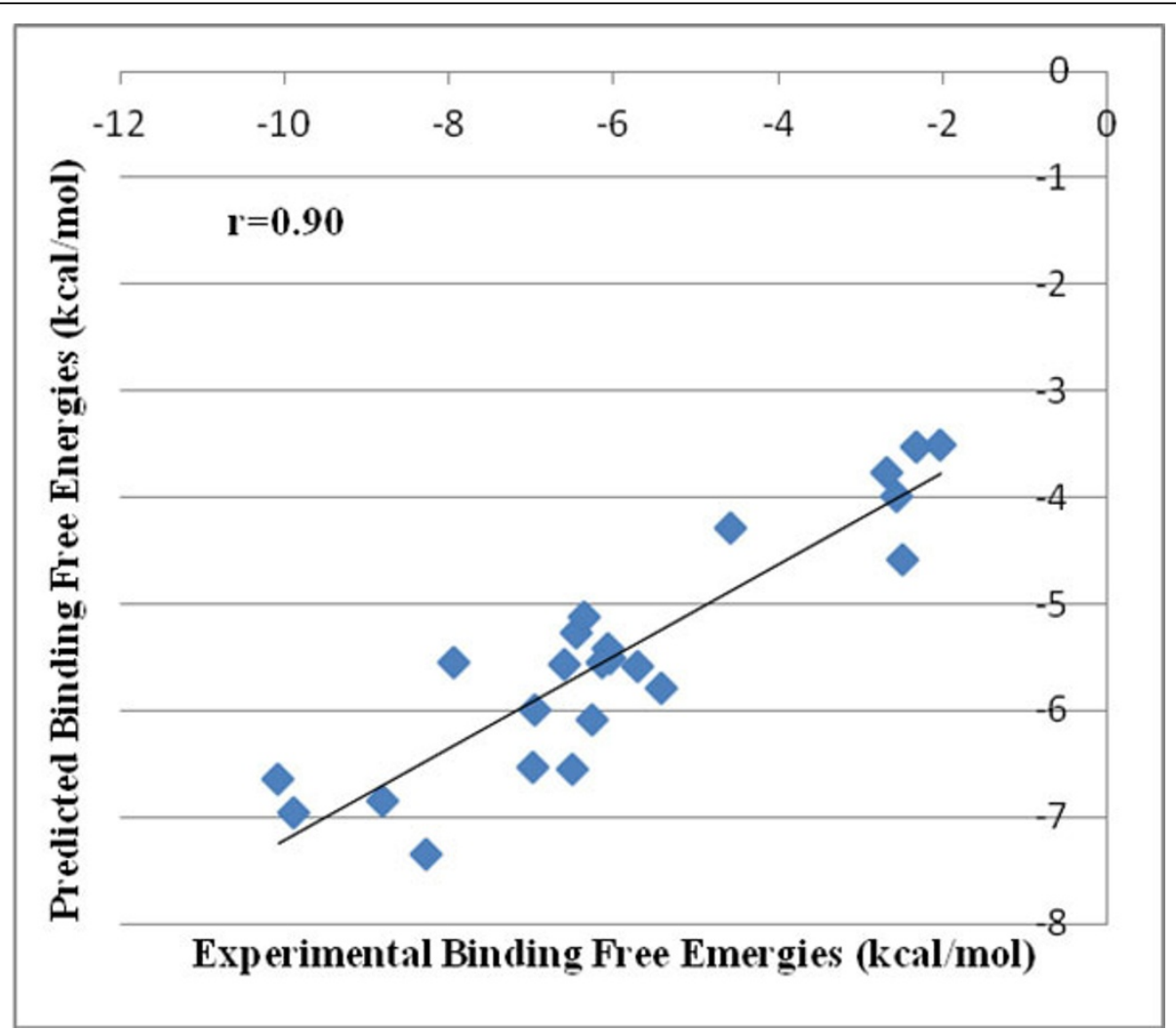

Figure 7 Correlation between experimental and predicted binding free energies of the top ranked docked structures for 23 trypsin binding molecules with unknown binding site information in the target protein. 
through Sanjeevini protocol in the above two case studies evident from a high correlation coefficient obtained (Figures 6 and 7) by two different methodologies taking care of inputs with known binding site and unknown binding site information in a protein target illustrates the strength of the Sanjeevini software.

\section{Future directions of Sanjeevini}

Improvements conceived in the future versions of Sanjeevini are: (i) consideration of the flexibility of the candidate ligand molecules, and the active site amino acids of the target, (ii) docking and scoring of the candidate molecules in the presence of a cofactor or multiple metal ions, (iii) extension of the DNA docking and scoring methodology to DNA binding intercalators and eventually (iv) creating an assembly line from genomes to hits [130].

\section{Conclusions}

This article presents Sanjeevini, a state of the art, structure based computer aided drug discovery (SBDD/ CADD) software suite implemented on an 80 processor cluster and presented to the user as a freely accessible server. The high accuracy of the modules and a user friendly environment should help the user in designing novel lead compounds.

\section{Availability and requirements}

Project name: Sanjeevini

Project home page: http://www.scfbio-iitd.res.in/sanjeevini/sanjeevini.jsp

Operating systems: Linux

Programming languages: $\mathrm{C}++$ and java

Any restrictions to use by non-academics: none

A detailed tutorial with various inputs and outputs of Sanjeevini in the form of snapshots is available at the following link http://www.scfbio-iitd.res.in/sanjeevini/ example/Tutorial.pdf. The coordinates of the validation dataset of 335 protein/DNA targets are available at the following link http://www.scfbio-iitd.res.in/sanjeevini/ dataset.jsp.

\section{Additional material}

Additional file 1: Validation of Sanjeevini scoring function on 366 Protein/DNA-ligand complexes.

Additional file 2: Docking and scoring studies on 335 Protein/DNA drug targets via Sanjeevini.

\section{Acknowledgements}

This work is carried out under programme support to computational biology from the Department of Biotechnology, Govt. of India. Ms. Tanya Singh is a recipient of Senior Research Fellowship from Council of Scientific \& Industrial Research, Govt. of India. Goutam Mukherjee is a recipient of Senior Research
Fellowship from the University Grants Commission. The authors are thankful to Mr. Bharat Lakhani, for help in web-enabling the current version of Sanjeevini.

This article has been published as part of BMC Bioinformatics Volume 13 Supplement 17, 2012: Eleventh International Conference on Bioinformatics (InCoB2012): Bioinformatics. The full contents of the supplement are available online at http://www.biomedcentral.com/bmcbioinformatics/ supplements/13/S17.

\section{Author details}

'Department of Chemistry, Indian Institute of Technology, Hauz Khas, New Delhi-110016, India. ${ }^{2}$ Supercomputing Facility for Bioinformatics \& Computational Biology, Indian Institute of Technology, Hauz Khas, New Delhi-110016, India. ${ }^{3}$ Kusuma School of Biological Sciences, Indian Institute of Technology, Hauz Khas, New Delhi-110016, India.

\section{Authors' contributions}

BJ designed the study. TS, GM and AM collected the data. BJ \& TS analyzed the data and wrote the manuscript. SS \& VS web-enabled the software.

\section{Competing interests}

The authors declare that they have no competing interests.

Published: 13 December 2012

\section{References}

1. Shaikh S, Jain T, Sandhu G, Latha N, Jayaram B: A physico-chemical pathway from targets to leads. Current Pharmaceutical Design 2007, 13:3454-3470.

2. Yamada $M$, Itai $A$ : Development of an efficient automated docking method. Chem Pharm Bull 1993, 41:1200-1202

3. Mizutani MY, Tomioka N, Itai A: Rational automatic search method for stable docking models of protein and ligand. J Mol Biol 1994, 243:310-326.

4. Mizutani MY, Takamatsu Y, Ichinose T, Nakamura K, Itai A: Effective handling of induced-fit motion in flexible docking. Proteins Struct Funct Genet 2006, 63:878-891.

5. Morris GM, Goodsell DS, Halliday RS, Huey R, Hart WE, Belew RK, Olson AJ: Automated docking using a Lamarckian genetic algorithm and an empirical binding free energy function. J Comput Chem 1998, 19:1639-1662.

6. Osterberg F, Morris GM, Sanner MF, Olson AJ, Goodsell DS: Automated docking to multiple target structures: incorporation of protein mobility and structural water heterogeneity in autodock. Proteins Struct Funct Genet 2002, 46:34-40.

7. Trott O, Olson AJ: AutoDock Vina: improving the speed and accuracy of docking with a new scoring function, efficient optimization and multithreading. Journal of Computational Chemistry 2010, 31:455-461.

8. Wu G, Robertson DH, Brooks CL III, Vieth M: Detailed analysis of gridbased molecular docking: a case study of CDOCKER-a CHARMm-based MD docking algorithm. J Comput Chem 2003, 24:1549-1562.

9. Vieth $M$, Hirst JD, Kolinski A, Brooks CL III: Assessing energy functions for flexible docking. J Comput Chem 1998, 19:1612-1622.

10. Lawrence MC, Davis PC: CLIX: a search algorithm for finding novel ligands capable of binding proteins of known three-dimensional structure. Proteins Struct Funct Genet 1992, 12:31-41.

11. Taylor JS, Burnett RM: DARWIN: a program for docking flexible molecules. Proteins Struct Funct Genet 2000, 41:173-191.

12. Clark KP, Jain AN: Flexible ligand docking without parameter adjustment across four ligand-receptor complexes. J Comput Chem 1995, 16:1210-1226.

13. Rohs R, Bloch I, Sklenar H, Shakked Z: Molecular flexibility in ab-initio drug docking to DNA: Binding-site and binding-mode transitions in all-atom Monte Carlo simulations. Nucleic Acids Res 1995, 33:7048-7057.

14. Oshiro CM, Kuntz ID, Dixon JS: Flexible ligand docking using a genetic algorithm. J Comput Aided Mol Des 1995, 9:113-130.

15. Knegtel RMA, Kuntz ID, Oshiro CM: Molecular docking to ensembles of protein structures. J Mol Biol 1997, 266:424-440.

16. Kang $X$, Shafer $\mathrm{RH}$, Kuntz ID: Calculation of ligand-nucleic acid binding free energies with the generalized-born model in DOCK. Biopolymers 2004, 73:192-204. 
17. Moustakas DT, Lang PT, Pegg S, Pettersen E, Kuntz ID, Brooijmans N, Rizzo RC: Development and validation of a modular, extensible docking program: DOCK 5. J Comput Aided Mol Des 2006, 20:601-619.

18. Irwin JJ, Shoichet BK, Mysinger MM, Huang N, Colizzi F, Wassam P, Cao Y: Automated docking screens: a feasibility study. J Med Chem 2009, 52:5712-5720.

19. Hart TN, Read RJ: A multiple-start Monte Carlo docking method. Proteins Struct Funct Genet 1992, 13:206-222.

20. Vieth M, Cummins DJ: DoMCoSAR: a novel approach for establishing the docking mode that is consistent with the structure-activity relationship. Application to HIV-1 protease inhibitors and VEGF receptor tyrosine kinase inhibitors. J Med Chem 2000, 43:3020-3032.

21. Schafferhans A, Klebe G: Docking ligands onto binding site representations derived from proteins built by homology modelling. $J$ Mol Biol 2001, 307:407-427.

22. Grosdidier A, Zoete V, Michielin O: EADock: docking of small molecules into protein active sites with a multiobjective evolutionary optimization. Proteins Struct Funct Genet 2007, 67:1010-1025.

23. Zsoldos Z, Reid D, Simon A, Sadjad BS, Johnson AP: eHiTS: an innovative approach to the docking and scoring function problems. Curr Protein Pept Sci 2006, 7:421-435.

24. Pang YP, Perola E, Xu R, Prendergast FG: EUDOC: a computer program for identification of drug interaction sites in macromolecules and drug leads from chemical databases. J Comput Chem 2001, 22:1750-1771.

25. Taylor RD, Jewsbury PJ, Essex JW: FDS: flexible ligand and receptor docking with a continuum solvent model and soft-core energy function. J Comput Chem 2003, 24:1637-1656.

26. Majeux N, Scarsi M, Apostolakis J, Ehrhardt C, Caflisch A: Exhaustive docking of molecular fragments with electrostatic solvation. Proteins Struct Funct Genet 1999, 37:88-105.

27. Budin N, Majeux N, Caflisch A: Fragment-based flexible ligand docking by evolutionary optimization. Biol Chem 2001, 382:1365-1372.

28. Kolb P, Caflisch A: Automatic and efficient decomposition of twodimensional structures of small molecules for fragment-based highthroughput docking. J Med Chem 2006, 49:7384-7392.

29. Corbeil CR, Englebienne P, Moitessier N: Docking ligands into flexible and solvated macromolecules. 1. Development and validation of FITTED 1.0. J Chem Inf Model 2007, 47:435-449.

30. Rarey M, Kramer B, Lengauer T, Klebe GA: Fast flexible docking method using an incremental construction algorithm. J Mol Biol 1996, 261:470-489.

31. Rarey $M$, Kramer $B$, Lengauer $T$ : The particle concept: placing discrete water molecules during protein-ligand docking predictions. Proteins Struct Funct Genet 1999, 34:17-28.

32. Clausen $H$, Buning C, Rarey M, Lengauer T: FLEXE: efficient molecular docking considering protein structure variations. J Mol Biol 2001, 308:377-395.

33. Zhao Y, Sanner MF: FLIPDock: docking flexible ligands into flexible receptors. Proteins Struct Funct Bioinf 2007, 68:726-737.

34. Miller MD, Kearsley SK, Underwood DJ, Sheridan RP: FLOG: a system to select 'quasi-flexible' ligands complementary to a receptor of known three-dimensional structure. J Comput Aided Mol Des 1994, 8:153-174.

35. McGann MR, Almond HR, Nicholls A, Grant JA, Brown FK: Gaussian docking functions. Biopolymers 2003, 68:76-90.

36. Gabb HA, Jackson RM, Sternberg MJE: Modelling protein docking using shape complementarity, electrostatics and biochemical information. J Mol Biol 1997, 272:106-120

37. Charifson PS, Corkery JJ, Murcko MA, Walters WP: Consensus scoring: a method for obtaining improved hit rates from docking databases of three-dimensional structures into proteins. J Med Chem 1999, 42:5100-5109.

38. Li H, Li C, Gui C, Luo X, Chen K, Shen J, Wang X, Jiang H: GAsDock: a new approach for rapid flexible docking based on an improved multipopulation genetic algorithm. Bioorg Med Chem Lett 2004, 14:4671-4676.

39. Yang JM, Chen CC: GEMDOCK: a generic evolutionary method for molecular docking. Proteins Struct Funct Bioinf 2004, 55:288-304.

40. Tietze S, Apostolakis J: GlamDock: development and validation of a new docking tool on several thousand protein-ligand complexes. J Chem Inf Model 2007, 47:1657-1672.

41. Friesner RA, Banks JL, Murphy RB, Halgren TA, Klicic JJ, Mainz DT, Repasky MP, Knoll EH, Shelley M, Perry JK, Shaw DE, Francis P, Shenkin PS: Glide: a new approach for rapid, accurate docking and scoring. 1.
Method and assessment of docking accuracy. J Med Chem 2004, 47:1739-1749.

42. Sherman W, Day T, Jacobson MP, Friesner RA, Farid R: Novel procedure for modeling ligand/receptor induced fit effects. J Med Chem 2006, 49:534-553.

43. Verdonk ML, Cole JC, Hartshorn MJ, Murray CW, Taylor RD: Improved protein-ligand docking using GOLD. Proteins Struct Funct Genet 2003, 52:609-623.

44. Verdonk ML, Chessari G, Cole JC, Hartshorn MJ, Murray CW, Nissink JWM, Taylor RD, Taylor R: Modeling water molecules in protein-ligand docking using GOLD. J Med Chem 2005, 48:6504-6515.

45. Welch W, Ruppert J, Jain AN: Hammerhead: fast, fully automated docking of flexible ligands to protein binding sites. Chem Biol 1996, 3:449-462.

46. Dominguez C, Boelens R, Bonvin AMJJ: HADDOCK: a protein-protein docking approach based on biochemical or biophysical information. J Am Chem Soc 2003, 125:1731-1737.

47. Floriano WB, Vaidehi N, Zamanakos G, Goddard WA III: HierVLS hierarchical docking protocol for virtual ligand screening of large-molecule databases. J Med Chem 2004, 47:56-71.

48. Trabanino RJ, Hall SE, Vaidehi N, Floriano WB, Kam WWT, Goddard WA III: First principles predictions of the structure and function of G-proteincoupled receptors: validation for bovine rhodopsin. Biophys J 2004, 86:1904-1921.

49. Abagyan R, Totrov M, Kuznetsov D: ICM-a new method for protein modeling and design: applications to docking and structure prediction from the distorted native conformation. J Comput Chem 1994, 15:488-506.

50. Totrov $M$, Abagyan R: Flexible protein-ligand docking by global energy optimization in internal coordinates. Proteins Struct Funct Genet 1997, 29:215-220.

51. Diller DJ, Merz KM Jr: High throughput docking for library design and library prioritization. Proteins Struct Funct Genet 2001, 43:113-124.

52. Wu SY, McNae I, Kontopidis G, McClue SJ, Mclnnes C, Stewart KJ, Wang S, Zheleva DI, Marriage H, Lane DP, Taylor P, Fischer PM, Walkinshaw MD: Discovery of a novel family of CDK inhibitors with the program LIDAEUS: structural basis for ligand-induced disordering of the activation loop. Structure 2003, 11:399-410.

53. Sobolev V, Wade RC, Vriend G, Edelman M: Molecular docking using surface complementarity. Proteins Struct Funct Genet 1996, 25:120-129.

54. Fradera X, Kaur J, Mestres J: Unsupervised guided docking of covalently bound ligands. I Comput Aided Mol Des 2004, 18:635-650.

55. Liu M, Wang S: MCDOCK: a Monte Carlo simulation approach to the molecular docking problem. J Comput Aided Mol Des 1999, 13:435-451.

56. Thomsen R, Christensen MH: MolDock: A new technique for highaccuracy molecular docking. J Med Chem 2006, 49:3315-3321.

57. Schneidman-Duhovny D, Inbar $Y$, Nussinov R, Wolfson HJ: PatchDock and SymmDock: servers for rigid and symmetric docking. Nucleic Acids Res 2005, 33:363-367.

58. Tøndel K, Anderssen E, Drabløs F: Protein Alpha Shape (PAS) Dock: A new gaussian-based score function suitable for docking in homology modelled protein structures. J Comput Aided Mol Des 2006, 20:131-144.

59. Joseph-MCCarthy D, Thomas BE IV, Belmarsh M, Moustakas D, Alvarez JC: Pharmacophore-based molecular docking to account for ligand flexibility. Proteins Struct Funct Gene 2003, 51:172-188.

60. Goto J, Kataoka R, Hirayama N: Ph4Dock: pharmacophorebased proteinligand docking. J Med Chem 2004, 4:6804-6811.

61. Kozakov D, Brenke R, Comeau SR, Vajda S: PIPER: an FFTbased protein docking program with pairwise potentials. Proteins Struct Funct Genet 2006, 65:392-406.

62. Korb O, Stutzle T, Exner TE: PLANTS: application of ant colony optimization to structure-based drug design. Lecture Notes in Computer Science (Including Subseries Lecture Notes in Artificial Intelligence and Lecture Notes in Bioinformatics). Brussels 2006, 247-258.

63. Trosset JY, Scheraga HA: PRODOCK: software package for protein modeling and docking. J Comput Chem 1999, 20:412-427.

64. Murray CW, Baxter CA, Frenkel AD: The sensitivity of the results of molecular docking to induced fit effects: application to thrombin, thermolysin and neuraminidase. J Comput Aided Mol Des 1999, 13:547-562.

65. Seifert MHJ: ProPose: steered virtual screening by simultaneous proteinligand docking and ligand-ligand alignment. J Chem Inf Model 2005, 45:449-460. 
66. Pei J, Wang Q, Liu Z, Li Q, Yang K, Lai L: PSI-DOCK: towards highly efficient and accurate flexible ligand docking. Proteins Struct Funct Genet 2006, 62:934-946.

67. Jackson RM: Q-fit: a probabilistic method for docking molecular fragments by sampling low energy conformational space. J Comput Aided Mol Des 2002, 16:43-57

68. McMartin C, Bohacek RS: QXP: powerful, rapid computer algorithms for structure-based drug design. J Comput Aided Mol Des 1997, 11:333-344.

69. Morley SD, Afshar M: Validation of an empirical RNA-ligand scoring function for fast flexible docking using RiboDocks. J Comput Aided Mol Des 2004, 18:189-208.

70. Meiler J, Baker D: ROSETTALIGAND: protein-small molecule docking with full side-chain flexibility. Proteins Struct Funct Genet 2006, 65:538-548.

71. Burkhard P, Taylor P, Walkinshaw MD: An example of a protein ligand found by database mining: description of the docking method and its verification by a $2.3 \mathrm{~A}^{\circ} \mathrm{X}$-ray structure of a thrombin-ligand complex. J Mol Biol 1998, 277:449-466.

72. Wu G, Vieth M: SDOCKER: a method utilizing existing X-ray structures to improve docking accuracy. J Med Chem 2004, 47:3142-3148.

73. Schnecke $V$, Kuhn LA: Virtual screening with solvation and ligand-induced complementarity. Persp Drug Discov Des 2000, 20:171-190.

74. Zavodszky MI, Kuhn LA: Side-chain flexibility in protein-ligand binding: the minimal rotation hypothesis. Protein Sci 2005, 14:1104-1114.

75. Alberts IL, Todorov NP, Dean PM: Receptor flexibility in de novo ligand design and docking. J Med Chem 2005, 48:6585-6596.

76. Chen HM, Liu BF, Huang HL, Hwang SF, Ho SY: SODOCK: Swarm optimization for highly flexible protein-ligand docking. J Comput Chem 2007, 28:612-623.

77. Fradera $X$, Knegtel RMA, Mestres J: Similarity-driven flexible ligand docking. Proteins Struct Funct Genet 2000, 40:623-636.

78. Jain AN: Surflex: fully automatic flexible molecular docking using a molecular similarity-based search engine. J Med Chem 2003, 46:499-511.

79. Jain AN: Surflex-Dock 2.1: robust performance from ligand energetic modeling, ring flexibility, and knowledge-based search. J Comput Aided Mol Des 2007, 21:281-306.

80. Choi V: YUCCA: an efficient algorithm for small-molecule docking. Chem Biodivers 2005, 2:1517-1524.

81. Khanna V, Ranganathan S: In silico approach to screen compounds activeagainst parasitic nematodes of major socioeconomic importance. BMC Bioinformatics 2011, 12(Suppl 13):S25

82. Rastelli G, Pacchioni S, Sirawaraporn W, Sirawaraporn R, Parenti MD, Ferrari AM: Docking and database screening reveal new classes of Plasmodium falciparum dihydrofolate reductase inhibitors. Journal of Medicinal Chemistry 2003, 46(14):2834-45.

83. Kapetanovic IM: COMPUTER-AIDED DRUG DISCOVERY AND DEVELOPMENT (CADDD): in silico-chemico-biological approach. Chem Biol Interact 2008, 171(2):165-176.

84. Talele T, Khedkar SA, Rigby AC: Successful applications of computer aided drug discovery: moving drugs from concept to the clinic. Curr Top Med Chem 2010, 10(1):127-41.

85. Ooms F: Molecular modeling and computer aided drug design. Examples of their applications in medicinal chemistry. Current Medicinal Chemistry 2000, 7:141-158.

86. Douglas BK, Decornez H, Furr JR, Bajorath J: Docking and scoring in virtual screening for drug discovery: methods and applications. Nature Reviews Drug Discovery 2004, 3:935-949.

87. Ekins S, Mestres J, Testa B: In silico pharmacology for drug discovery: methods for virtual ligand screening and profiling. Br J Pharmacol 2007, 152(1):9-20.

88. Pang YP: In Silico Drug Discovery: Solving the "target-rich and lead-poor" imbalance using the genome-to-drug-lead paradigm. Clinical Pharmacology \& Therapeutics 2007, 81:30-34

89. Rao VS, Srinivas K: Modern drug discovery process: an in silico approach. Journal of Bioinformatics and Sequence Analysis 2011, 2(5):89-94.

90. Singh Tanya, Biswas D, Jayaram B: A robust active site identification protocol based on physico-chemical descriptors lining the cavities in proteins. J Chem Inf Modeling 2011, 51(10):2515-2527.

91. Irwin JJ, Shoichet BK: ZINC - free database of commercially available compounds for virtual screening. J Chem Inf Model 2005, 45:177-182.

92. Jakalian A, Bush BL, Jack DB, Bayly Cl: Fast, efficient generation of highquality atomic charges. AM1-BCC model: I. Method. J Comput Chem 2000, 21:132-146.
93. Mukherjee G, Patra N, Barua P, Jayaram B: A fast empirical GAFF compatible partial atomic charge assignment scheme for modeling interactions of small molecules with biomolecular targets. J Comput Chem 2011, 32:893-907.

94. Wang J, Wolf RM, Caldwell JW, Kollman PA, Case DA: Development and testing of a general amber force field. J Comput Chem 2004, 25:1157-1174.

95. Cornell WD, Cieplak P, Bayly Cl, Gould IR, Merz KM, et al: A second generation force field for the simulation of proteins, nucleic acids, and organic molecules. J Am Chem Soc 1995, 117:5179-5197.

96. Gupta A, Gandhimathi P, Sharma P, Jayaram B: ParDOCK: An all atom energy based Monte Carlo docking protocol for protein-ligand complexes. Protein Pept Lett 2007, 14:632-46.

97. Jain $T$, Jayaram B: An all atom energy based computational protocol for predicting binding affinities of protein-ligand complexes. FEBS Letters 2005, 579:6659-6666.

98. Jain T, Jayaram B: Computational protocol for predicting the binding affinities of Zinc containing metalloprotein-ligand complexes. PROTEINS: Struct Funct Bioinfo 2007, 67:1167-1178.

99. Shaikh S, Jayaram B: A swift all atom energy based computational protocol to predict DNA-Drug binding affinity and $\Delta \mathrm{Tm}$. J Med Chem 2007, 50:2240-2244.

100. Shaikh SA, Ahmed SR, Jayaram B: A molecular thermodynamic view of DNA-drug interaction: a case study of 25 minor groove binders. Arch Biochem Biophys 2004, 429:81-99.

101. Kalra P, Reddy V, Jayaram B: A free energy component analysis of HIV-I protease - inhibitor binding. J Med Chem 2001, 44:4325-4338.

102. Lipinski CA: Lead- and drug-like compounds: the rule-of-five revolution. Drug Discovery Today: Technologies 2004, 1:337-341.

103. Lipinski CA, Lombardo F, Dominy BW, Feeney PJ: Experimental and computational approaches to estimate solubility and permeability in drug discovery and development settings. Adv Drug Delivery Rev 1997 23:3-25.

104. Berman HM, Westbrook J, Feng Z, Gilliland G, Bhat TN, Weissig H, Shindyalov IN, Bourne PE: The Protein Data Bank. Nucleic Acids Res 2000, 28:235-242.

105. Pearlman DA, Case DA, Caldwell JW, Ross WS, Cheathem JE III, et al: AMBER, a package of computer programs for applying molecular mechanics, normal mode analysis, molecular dynamics and free energy calculations to simulate the structural and energetic properties of molecules. Comput Phys Commun 1995, 91:1-41.

106. Zhang C, Liu S, Zhu Q, Zhou Y: A knowledge based energy function for protein-ligand, protein-protein and protein-DNA complexes. J Med Chem 2005, 48:2325-2335.

107. Wang $\mathrm{R}$, Lai $\mathrm{L}$, Wang S: Further development and validation of empirical scoring functions for structure-based binding affinity prediction. J Comput Aided Mol Des 2002, 16:11-26.

108. DeWitte RS, Shakhnovich El: SMoG: de novo design method based on simple, fast and accurate free energy estimates. Methodology and supporting evidence. J Am Chem Soc 1996, 118:11733-11744.

109. Mitchell JBO, Laskowski RA, Alex A, Thornton JM: BLEEP: potential of mean force describing protein-ligand interactions: II. Calculation of binding energies and comparison with experimental data. J Comp Chem 1999 20:1177-1185.

110. Muegge I, Martin YC: A general and fast scoring function for proteinligand interactions: a simplified potential approach. J Med Chem 1999 42:791-804.

111. Wang $R$, Liu L, Lai $L$, Tang Y: SCORE: a new empirical method for estimating the binding affinity of a protein-ligand complex. $J$ Mol Model 1998, 4:379-394.

112. Bohm HJ: Prediction of binding constants of protein-ligands: a fast method for the prioritization of hits obtained from de novo design or 3D database search programs. J Comput Aided Mol Des 1998, 12:309-323

113. Eldridge MD, Murray CW, Auton TR, Paolini GV, Mee RP: Empirical scoring functions: I. The development of a fast empirical scoring function to estimate the binding affinity of ligands in receptor complexes. $J$ Comput Aided Mol Des 1997, 11:425-445.

114. Krammer A, Kirchhoff PD, Jiang X, Venkatachalam CM, Waldman M: LigScore: a novel scoring function for predicting binding affinities. $J \mathrm{Mol}$ Graph Model 2005, 23:395-407. 
115. Cheng T, Liu Z, Wang R: A knowledge-guided strategy for improving the accuracy of scoring functions in binding affinity prediction. BMC Bioinformatics 2010, 11:193.

116. Zhao X, Liu X, Wang Y, Chen Z, Kang L, Zhang H, Luo X, Zhu W, Chen K, $\mathrm{Li} H$, Wang $X$, Jiang $H$ : An improved PMF scoring function for universally predicting the interactions of a ligand with protein, DNA, and RNA. J Chem Inf Model 2008, 48(7):1438-47.

117. Raha K, Merz KM Jr: A quantum mechanics based scoring function: study of zinc ion-mediated ligand binding. J Am Chem Soc 2004, 126:1020-1021.

118. Hou T, Zhang $W, X u X J$ : Binding affinities for a series of selective inhibitors of gelatinase-A using molecular dynamics with a linear interaction energy approach. J Phys Chem B 2001, 105:5304-5315.

119. Hu X, Shelver WH: Docking studies of matrix metalloproteinase inhibitors: zinc parameter optimization to improve the binding free energy prediction. J Mol Graph Model 2003, 22:115-126.

120. Rizzo RC, Toba S, Kuntz ID: A molecular basis for the selectivity of thiadiazole urea inhibitors with stromelysin- 1 and gelatinase-A from generalized born molecular dynamics simulations. J Med Chem 2004, 47:3065-3074.

121. Khandelwal A, Lukacova V, Comez D, Kroll DM, Raha S, Balaz S: A combination of docking, QM/MM methods, and MD simulation for binding affinity estimation of metalloprotein ligands. J Med Chem 2005, 48:5437-5447.

122. Xie ZR, Hwang MJ: An interaction-motif-based scoring function for protein-ligand docking. BMC Bioinformatics 2010, 11:298.

123. Arnott S, Campbell-Smith PJ, Chandrasekaran R: In handbook of biochemistry and molecular biology. In Nucleic Acids-Volume II.. 3 edition. Cleveland: CRC Press;Fasman GP 1976:411-422.

124. Beveridge DL, Barreiro G, Byun KS, Case DA, Cheatham TE, Dixit SB, Giudice E, Lankas F, Lavery R, Maddocks JH, Osman R, Seibert E, Sklenar H, Stoll G, Thayer KM, Varnai P, Young MA: Molecular dynamics simulations of the 136 unique tetranucleotide sequences of DNA oligonucleotides. I. research design and results on $\mathrm{d}(\mathrm{CpG})$ steps. Biophysical Journal 2004, 87(6):3799-3813

125. Lavery R, Zakrzewska K, Beveridge DL, Bishop TC, Case DA, Cheatham T III, Dixit S, Jayaram B, Lankas F, Laughton C, Maddocks JH, Michon A, Osman R, Orozco M, Perez A, Singh T, Spackova N, Sponer J: A systematic molecular dynamics study of nearest neighbor effects on base pair and base pair step conformations and fluctuations in B-DNA. Nucleic Acids Research 2009, 38(1):299-313.

126. Kinnings SL, Xie L, Fung KH, Jackson RM, Xie L, Bourne PE: The Mycobacterium tuberculosis Drugome and Its Polypharmacological Implications. PLoS Comput Biol 2010, 6(11).

127. Antalis TM, Buzza MS, Hodge KM, Hooper JD, Netzel-arnett S: The cutting edge: membrane-anchored serine protease activities in the pericellular microenvironment. Biochem J 2010, 428:325-346.

128. Li L, Dantzer JJ, Nowacki J, O'Callaghan BJ, Meroueh SO: PDBcal: a comprehensive dataset for receptor-ligand interactions with threedimensional structures and binding thermodynamics from isothermal titration calorimetry. Chem Biol Drug Des 2008, 71:529-532.

129. Talhout R, Engberts BFN: Thermodynamic analysis of binding of p-substituted benzamidines to trypsin. Eur J Biochem 2001, 268:1554-1560.

130. Soni A, Menaria K, Ray P, Jayaram B: Genomes to hits in Silico - a country path today, a highway tomorrow: a case study of Chikungunya. Current Pharmaceutical Design 2012, accepted for publication.

\section{Submit your next manuscript to BioMed Central and take full advantage of:}

- Convenient online submission

- Thorough peer review

- No space constraints or color figure charges

- Immediate publication on acceptance

- Inclusion in PubMed, CAS, Scopus and Google Scholar

- Research which is freely available for redistribution

Submit your manuscript at www.biomedcentral.com/submit
Biomed Central 